\title{
Relação família - escola e políticas públicas no Brasil e em Portugal: um estudo da regulamentação da participação parental na gestão escolar
}

\author{
Rosilane Kátia de Oliveira ${ }^{1}$ \\ Marlice de Oliveira e Nogueira² \\ Regina Magna Bonifácio de Araújo
}

\section{Resumo}

A partir de uma revisão da literatura, este trabalho discute as legislações portuguesa e brasileira objetivando compreender como os dois países tratam oficialmente o tema da relação entre família e escola, com foco central de análise, a legislação sobre a participação parental na gestão escolar. Os resultados evidenciam que, enquanto em Portugal houve um movimento associativo dos pais, no Brasil, mesmo que se observe uma regulamentação da participação parental na escolarização dos filhos, não se verifica a evidência de algum tipo de movimento associativo de pais e não há clareza sobre os modos como as famílias devem participar da vida escolar da prole.

Palavras-chave: Famílias; Gestão escolar; Legislação; Participação parental.

\section{Family-school relations and public policies in Brazil and Portugal: a study on the regulation of parental} participation in school management

\section{Abstract}

Based on a review of the literature, this paper discusses Portuguese and Brazilian legislation in order to understand how the two countries deal officially with the family-school relationship, with a central focus of analysis, legislation on parental participation in school management. The results show that, while in Portugal there was an associative movement of parents in Brazil, even if parental participation regulation is observed in the children's schooling, there is no evidence of any type of associative movement of parents and there is no clarity about the ways in which families should participate in children' school life.

Keywords: Families; School management; Legislation; Parental participation.

\section{Introdução}

Investigar a relação entre a família e a escola é adentrar em um terreno de tensões e conflitos, em que as relações entre os sujeitos envolvidos no processo educacional são construídas com movimentos de aproximações e/ou distanciamentos. Segundo Silva (2003), essa relação acontece em duas vertentes: escola e lar; e em duas dimensões de atuação: individual e

\footnotetext{
${ }^{1}$ Universidade Federal de Ouro Preto - Ouro Preto/MG. Endereço Eletrônico: rosilanekatia@yahoo.com.br

${ }^{2}$ Universidade Federal de Ouro Preto - Ouro Preto/MG. Endereço Eletrônico: nogueira_mar@uol.com.br

${ }^{3}$ Universidade Federal de Ouro Preto - Ouro Preto/MG. Endereço Eletrônico: regina.magna@hotmail.com
}

$$
\text { Periódico Horizontes - USF - Itatiba, SP-Brasil - e019008 }
$$


coletiva.

$\mathrm{Na}$ vertente escolar são consideradas todas as atividades realizadas na escola, tanto individuais quanto coletivas, por iniciativas de pais, professores, alunos ou outros atores. Nesta vertente, incluem-se as reuniões escolares realizadas com participação de pais e professores, e também as atividades desenvolvidas com a participação dos encarregados da educação em reuniões de Associações de Pais ou em órgãos da escola, tais como colegiados e conselhos (SILVA, 2003). Segundo Silva (2003), essas atividades configuram-se como a faceta mais visível da relação entre a escola e a família. No entanto, o autor sublinha que na vertente lar estão incluídas todas as atividades escolares desenvolvidas em casa, como a realização pelos filhos das diversas e multifacetadas tarefas escolares, o acompanhamento parental dessas atividades, e todo o tipo de iniciativa desenvolvida pela família em prol da escolarização da prole.

A dimensão individual abarca todas a atividades relacionadas ao processo de escolarização desenvolvido por cada familiar (pai, mãe, irmãos, parentes), estudante ou professor, ou seja, atividades realizadas individualmente pelos atores (SILVA, 2003). Já a dimensão coletiva caracteriza-se por uma atuação organizada, em que pais e alunos participam como representantes em associações ou como integrantes de órgãos colegiados ou consultivos da escola (SILVA, 2003).

Assim sendo, a interligação entre essas duas instâncias de socialização - a família e a escola - se dá, principalmente, por meio de um objetivo comum: o bom desempenho escolar dos filhos/estudantes. Quando não ocorre, por exemplo, o diálogo entre as duas instâncias socializadoras, o discurso mais presente, é de que essa ausência ou fragilidade pode afetar o desempenho escolar dos alunos. Nesse sentido, Nogueira (2006, p.157) argumenta que existe hoje "[...] uma ideologia da colaboração que produz a emergência de um discurso - tanto por parte dos profissionais de ensino, quanto por parte dos pais - que prega a importância e a necessidade do diálogo e da parceria entre as duas partes [...]". Porém, além deste ponto de vista, um discurso que preconiza a necessidade de interação entre escolas e famílias é estimulado e produzido, também, pelo Estado, “[...] na formulação de políticas públicas educacionais 
visando o desenvolvimento da participação e da cooperação entre as famílias e a escola [...]" (NOGUEIRA, 2006, p.156) nos países ocidentais. Em especial, no Brasil, Resende e Silva (2016, p.31) citam algumas ações desenvolvidas por órgãos oficiais para fomentar essa cooperação:

Dia Nacional da Família na Escola" (24 de abril), instituído pelo Ministério da Educação (MEC) no ano de 2001 e promovido por diversas redes de ensino desde então; a "Pesquisa Nacional Qualidade da Educação: a Escola Pública na opinião dos pais", realizada em 2005 pelo MEC; o Plano de Mobilização Social pela Educação (PMSE), lançado pelo MEC em 2008 como um "chamado [...] à sociedade para um trabalho voluntário de mobilização das famílias e da comunidade pela melhoria da qualidade da educação brasileira" (BRASIL, 2008, p. 1). Outras iniciativas poderiam também ser apontadas nos âmbitos estaduais e municipais, como o "Programa Escola da Família", desenvolvido desde 2003 pelo governo estadual de São Paulo, ou o "Projeto Família-Escola", mantido desde 2005 pela Prefeitura Municipal de Belo Horizonte.

Nesse contexto, Nogueira (2006) destaca que essas ações desenvolvidas pelo Estado brasileiro parecem ter como principal razão a promoção do sucesso escolar dos educandos, pois, várias pesquisas têm evidenciado o impacto positivo do envolvimento dos pais no desempenho acadêmico dos filhos, premissa que permeia os discursos políticos que sustentam essas ações.

Nesta senda, o presente artigo apresenta um estudo sobre as legislações portuguesa e brasileira que teve como objetivo compreender como estes dois países tratam oficialmente o tema da relação entre família e escola, tendo como foco central da análise, a legislação sobre a participação parental na gestão escolar, evidenciando os pontos de dissonância e consonância entre os dois contextos. Para tanto, o estudo está ancorado nos trabalhos de Silva (2003) sobre a legislação portuguesa e na pesquisa realizada por Resende e Silva (2016) acerca da regulamentação legal do tema no Brasil, bem como em outros documentos e textos pertinentes para a sua compreensão. Na primeira parte do artigo apresentamos uma descrição das legislações portuguesa e brasileira sobre relação entre família e escola, destacando os marcos históricos relevantes. Em seguida, uma análise das legislações sobre a participação parental na gestão escolar nos dois países é desenvolvida. E, para finalizar, as considerações finais fecham o trabalho, destacando aproximações e distanciamentos no que tange a participação parental em

Periódico Horizontes - USF - Itatiba, SP-Brasil - e019008 
Portugal e no Brasil.

\section{Legislação portuguesa e brasileira: delineando caminhos para a compreensão da relação entre família e escola}

De acordo com Silva e Stöer (2005), na esteira de Beattie (1985) destaca-se que a emergência da participação parental no mundo ocidental se deu mais por iniciativa do próprio Estado do que pelos movimentos populares, "[...] como uma resposta a uma crise de legitimação do Estado [...]" (SILVA; STÖER, 2005, p.14) e, de modo especial, em Portugal pela condição semiperiférica ${ }^{4}$ do país.

Silva (2003) afirma que o contexto de participação parental em grande parte dos países ocidentais se constituiu em um momento de expansão da escolarização secundária, tendo como marco a Segunda Guerra Mundial. As consequências deixadas pela guerra nesses países

[...] levou-os a uma autentica batalha pela produção e a procura de consensos sociais alargados, com a aposta na educação escolar como formadora de mão de obra qualificada para os vários níveis da estrutura econômica. O próprio contexto internacional, com o advento da guerra fria, ajudou a tal situação [...] (SILVA, 2003, p.184).

Percebe-se que, após o período de desastre ocasionado pela guerra, a educação passou a ser entendida como um mecanismo político, econômico e social necessário para reerguer os países por ela afetados, porém, o processo de escolarização não aconteceu de forma acelerada em todos os países ocidentais, naquele momento. Nessa direção, Silva (2003, p.184), ao embasar-se em Castro (1995), afirma que no "caso português a explosão escolar ter-se à iniciado

\footnotetext{
${ }^{4}$ Silva (2003, p.185) ao citar Carlos Fortuna (1987), Santos (1992) e Helena Araújo (1993, 1996, 2000) afirma que “ os países semiperiféricos tendem a possuir um Estado autoritário, interventor, centralista, aparentemente forte, mas com uma crise endémica de legitimação e em que a força dificilmente se converte na sua legitimação".
}

$$
\text { Periódico Horizontes - USF - Itatiba, SP-Brasil - e019008 }
$$


por volta de 1967 [...]", tendo como marco simbólico a data de 25 de Abril ${ }^{5}$ de 1974 "[...] que abriu as portas à democracia" (SILVA, 2003, p.184).

Para uma melhor compreensão do modo como se constituiu historicamente a emergência, em Portugal, de um discurso sobre participação ${ }^{6}$ parental na escolarização, desenvolvido em um contexto de mudanças socioeconômicas e políticas em curso na segunda metade do século XX, Silva (2003) considerou a existência de quatro períodos: 1) o período que precede o 25 de Abril de 1895 até 1973; 2) o período intenso entre 1974 e 1976; 3) o decênio 1976-1986 e 4) o período de 1986 a 2000.

Silva (2003) destaca o período que antecede o 25 de Abril de 1974 como um período longo e heterogêneo, tanto do ponto de vista dos regimes políticos vivenciados pelo país Monarquia, Primeira República e Estado Novo-, quanto das especificidades dos sistemas educativos. Segundo o autor, neste período, já havia indícios de uma representatividade formal dos encarregados de educação em órgãos escolares ou nos demais níveis do sistema educativo. Os diretores de Turma, o Conselho de Orientação Escolar e o Conselho de Turma apareceram na legislação de 1968, com a publicação do Estatuto do Ciclo Preparatório do Ensino Secundário, regulamentada pelo Decreto n. 948 572, de 9 de setembro. Silva (2003), ao fundamentar-se em Castro (1995), destaca as atribuições dos representantes desses órgãos colegiados. O Conselho de Orientação Escolar ficava responsável por deslindar os problemas relativos à vida dos alunos visando colaborar para a interligação entre a família e a escola. Já o Conselho de turma e o Diretor de turma tinham várias atribuições, e dentre elas, a responsabilidade de definir estratégias de participação dos pais na vida escolar buscando o estreitamento da relação entre escola e família. Nessa linha, Silva (2003, p.131, grifos do autor) afirma que

Como vemos, está-se ainda longe da representação formal dos encarregados de educação nas escolas ou de um movimento associativo dos pais legalmente

\footnotetext{
${ }^{5}$ O 25 de Abril de 1974 é uma data emblemática em Portugal (Dia da liberdade) porque representa o fim de uma ditadura de quase meio século, e o surgimento de muitos movimentos sociais de base popular. Assim "[...] toda uma sociedade podia de novo respirar, reencontrava sua voz, reconstruía sua identidade. (SILVA, 2003, p. 133).

${ }^{6}$ Conforme Silva $(2003$, p.83) “[...] O conceito de participação remete, antes, para a integração de órgãos da escola, de associações de pais, ou órgãos a outros níveis do sistema educativo [...]".
}

Periódico Horizontes - USF - Itatiba, SP-Brasil - e019008 
enquadrado e legitimado, mas à data do 25 de Abril, era já notória uma preocupação explícita em a escola promover alguma interação com as famílias, incluindo atividades dentro da escola.

Nota-se que a iniciativa de estreitamento da relação entre a família e a escola é estimulada primeiramente pela escola, pois, até então, ainda não se tinha um discurso explícito que recomendasse a participação parental na vida escolar e os "[...] pais ainda não eram considerados parceiros no processo educativo (não detendo capacidade de representação nem de associações" (SILVA, 2003, p.131). No entanto, é preciso destacar que, mesmo antes desse período, havia uma referência, como destacado na citação acima, apontando para a necessidade da participação dos pais na vida escolar dos filhos, embora a organização dessas ações ainda não estivesse, naquele momento, explícita e regulamentada pela legislação.

Silva (2003) discute que, no período próximo ao 25 de Abril, havia uma movimentação ampliada por várias escolas católicas femininas em Portugal, e que teve como resultado a criação da Escola Nacional de Pais. Embora fosse perceptível a incipiência do movimento associativo dos pais naquele momento, tal iniciativa se constituiu em "um embrião" que desempenharia um papel relevante e não poderia ser desconsiderado na análise do período seguinte (SILVA, 2003).

O segundo período (1974-1975), considerado por Silva (2003) como mais intenso, foi um momento de efervescência de diversos movimentos da sociedade civil impondo-se ao Estado português. Na educação, essa efervescência de contraposição social também deixa sua marca, “[...] alteram-se as relações de poder dentro das escolas e, durante algum tempo, entre estas e o poder central [...]" (SILVA, 2003, p.180). No entanto, mesmo com a eminência de algumas práticas democráticas na gestão escolar, os pais ainda não tinham seu direito de participação reconhecido e continuavam ausentes nos órgãos decisórios das escolas. Nesse sentido, Silva (2003) buscou compreender em suas pesquisas, os motivos da invisibilidade do movimento associativo dos pais neste período, considerado por ele como "pós 25 de abril", já que era "[...] um período de forte dinamismo social" (p.181).

Nessa perspectiva, Silva (2003), em referência a um outro texto escrito por ele em 1994, afirma que este movimento associativo dos pais era composto socialmente pela classe média e Periódico Horizontes - USF - Itatiba, SP-Brasil - e019008 
emanava um sentido político conservador, próprio desse segmento social naquele momento. Sendo assim, "[...] os pais não eram ainda um interlocutor socialmente legitimado. Seriam, antes, um ator social em construção" (p.182). Segundo o autor, possivelmente, a grande movimentação popular do período, de certa forma, pode ter influenciado para que estes movimentos conservadores de classe média, esmaecessem perante outros movimentos sociais, de maior visibilidade naquele momento.

Silva (2003) destaca que a publicação do despacho no 68/74 em 28 de novembro de 1974 diz respeito à gestão do ensino primário e a eleição do Diretor da escola é um elemento crucial no documento

[...] que se preocupa essencialmente com as questões processuais. $O$ conselho Escolar é constituído por todos os docentes da escola, mas prevê-se que o $\ll<0$ conselho Escolar pode decidir que a ele sejam agregados, com funções consultivas, representantes do pessoal auxiliar, dos encarregados de educação e de instituições interessadas no funcionamento da escola, designadamente autarquias locais >>. (SILVA, 2003, p.134, grifos do autor).

Como vemos, de acordo com o documento, os representantes citados no documento podiam ter participação no Conselho Escolar com funções consultivas e não decisórias, assim como parece também que o diretor escolar não tinha completa autonomia para resolver todas as questões que diziam respeito à escola. Como argumenta Silva (2003, p.134), “[...] no 1.o ciclo do ensino básico, a regulamentação passa pela eleição do diretor, mantendo o Ministério o controlo do essencial (programas, calendário escolar, legislação específica, colocação de professores e etc.) [...]".

Mais tarde, ainda segundo Silva (2003), o despacho no 40/75 de 21 de dezembro de 1975 substitui o despacho anterior, enfatizando a gestão democrática do ensino primário. Em relação ao conteúdo do documento, o autor argumenta que ele não traz algo novo, no entanto, constituise como um documento mais completo que o anterior, estabelecendo "[...] uma ligação entre as condições em que decorria a experiência democrática na sociedade e o tipo de gestão escolar [...]" (SILVA, 2003, p.135). Percebe-se, assim, a preocupação do Estado português em incentivar

Periódico Horizontes - USF - Itatiba, SP-Brasil - e019008 
práticas democráticas dentro das escolas, já que o país estava experimentando, naquele período, a instauração de um contexto político democrático. Silva (2003, p.135) acrescenta sobre o referido documento que "[...] embora não expresso com caráter obrigatório, cumpre incentivar a participação dos pais, sempre que possível através das suas associações, autarquias, comissões de moradores e de aldeias [...]".

Como vemos, o despacho no 68/74 de 28 de novembro enfatizava a gestão do ensino primário, enquanto no despacho no 40/75 de 21 de dezembro, a ênfase era a gestão democrática no mesmo nível de ensino. A diferença apresenta-se em relação ao caráter da gestão democrática no ensino primário, ou seja, parece que a legislação orientava que as escolas tivessem práticas democráticas em consonância com o momento político da sociedade portuguesa. Outro destaque também é que no despacho no 40/75 havia menção à participação dos pais por meio das associações.

Silva (2003) destaca que, quanto a declaração de princípios, o ponto 1.2 do despacho no 40/75 de 21 de Dezembro, definia a composição do Conselho Escolar de modo semelhante ao que estava expresso no despacho anterior, no qual o órgão podia decidir sobre a agregação dos encarregados de educação, dos representantes de alunos, de pessoal auxiliar, das autarquias locais e outras instituições de caráter sociocultural, com funções consultivas. O que diferencia este documento do anterior é a referência aos representantes de alunos e das instituições de cunho sociocultural (SILVA, 2003), ausentes no documento anterior.

No que concerne às competências do Diretor Escolar, o referido despacho em seu ponto 1.10 apontava a incumbência de "prestar colaboração às comissões de moradores, instituições de caráter cívico e associações de pais > - alínea j) - e <<atender os encarregados de educação, quando necessário > - alínea m)" (SILVA, 2003, p.135, grifos do autor). Já a sua função dentro do Conselho Escolar se resumia à cooperação ${ }^{7}$.

O Decreto-Lei no 735/74 consiste em uma primeira tentativa de implementação de uma

\footnotetext{
7 Silva (2003) aponta que no ponto 1.7 do despacho $n$ ㅇ 40/75, as funções do Conselho Escolar contemplam casos de cunho disciplinar, que são apresentados pelos professores, encarregados da educação, do diretor da escola e do pessoal escolar. Não compete a este órgão a interligação com as comunidades e as famílias.
}

Periódico Horizontes - USF - Itatiba, SP-Brasil - e019008 
gestão democrática nos ensinos preparatório e secundário, regulamentada pelos Conselhos Diretivos. Nesse contexto, Silva $(2003$, p.137) ressalta que

[...] tanto o despacho no 68/74, de 28 de novembro, como o Decreto-Lei no 735/74 de 21 de Dezembro (relativos à gestão respectivamente nos ensinos primários e preparatório/ secundário), convergem na demonstração de um primeiro sinal - retórico- enviado ao movimento associativo dos pais.

Percebe-se, assim, uma mudança significativa no modo de gestão no interior das escolas portuguesas, na primeira metade da década de 1970, porém, pouco se avançou em relação à participação parental. De acordo com Silva (2003), os pais, inclusive aqueles dos níveis secundário e preparatório, insatisfeitos com o modo de funcionamento dos sistemas de ensino e com a ausência de garantia legal para a representatividade dos pais, reuniram-se e mobilizaram-se para que as suas vozes fossem atendidas pelo poder político. Nessa mesma linha, o autor esclarece que a movimentação dos pais em prol de mais participação nos processos políticos educacionais desencadeou dois momentos: no primeiro nasceram muitas associações de pais de maneira informal, e num segundo momento, "[...] o embrião do futuro Secretariado Nacional das Associações de Pais (SNAP), tentativa clara (e bem-sucedida) de se constituírem em parceiros sociais [...]" (SILVA, 2003, p.138). Desse modo, o movimento organizado dos pais, juntamente com a criação do SNAP contribuíram para as transformações que ocorreram no período seguinte.

No período entre 1976 e 1985 configuraram-se muitas mudanças no cenário político português, constituindo-se uma fase conhecida como "normalização", sendo que, no ano de 1976, foi aprovada a Constituição da República e foram realizadas as primeiras eleições para a Assembleia da República. Sobre a relação da escola com a sociedade, Silva (2003, p.180) afirma que a Constituição de 1976, em seu artigo 74, n. -2 estabeleceu que "o Estado deve modificar o ensino de modo a superar a sua função conservadora da divisão social do trabalho". Quanto ao movimento associativo dos pais, pode-se afirmar que ele ganhou legitimidade por meio da aprovação em 1 de fevereiro de 1977, da Lei no 7/77, a primeira Lei das Associações de Pais e pela constituição formal da SNAP legalizada também na mesma data (SILVA, 2003).

E no Brasil, como se deu a regulamentação da participação parental na vida escolar e da

Periódico Horizontes - USF - Itatiba, SP-Brasil - e019008 
Associação de Pais?

De acordo com Resende e Silva (2016), no Brasil não há uma lei nacional que regulamente, especificamente, a Associação de Pais ${ }^{8}$. Segundo as autoras, alguns Estados e Municípios brasileiros regulamentam a Associação de Pais e Mestres (APM), destacando que esses órgãos têm como objetivo auxiliar a direção da escola, sem que, no entanto, funcionem como entidades em que os pais podem exercer sua voz de modo deliberativo.

Na legislação brasileira, a APM só veio a aparecer na década de 1960, por meio da primeira Lei de Diretrizes e Bases da Educação (Lei no 4024), promulgada em 20 de dezembro de 1961. Nesse contexto, a LDB de 1961, em seu artigo 115, determina que "a escola deve estimular a formação de associações de pais e professores". Nesse sentido, observamos que do ponto de vista legal, não havia naquele momento, uma obrigatoriedade para a criação das Associações de Pais e Mestres.

Mais tarde, em 11 de agosto de 1971, por meio da Lei no 5.692, em seu artigo 62, foi estabelecida a obrigatoriedade da existência de uma entidade que congregasse a participação de pais e professores nos estabelecimentos de ensino:

Cada sistema de ensino compreenderá obrigatoriamente, além de serviços de assistência educacional que assegurem aos alunos necessitados condições de eficiência escolar entidades que congreguem professores e pais de alunos, com o objetivo de colaborar para o eficiente funcionamento dos estabelecimentos de ensino (BRASIL, 1971).

Desse modo, observa-se que a participação dos pais na APM prevista na Lei no 5.692 visava um bom funcionamento dos sistemas de ensino, aproximando-se do apontamento feito por Resende e Silva (2016) em que essas associações tinham como objetivo auxiliar a gestão da escola.

No Brasil, a Constituição Federal vigente que legitima os direitos dos cidadãos, foi instituída em 1988. Nessa perspectiva, em referência ao tratamento do tema da relação entre

\footnotetext{
8 Resende e Silva (2016) identificaram nas análises dos documentos por elas investigados, a única referência a Associação de Pais, foi encontrada recentemente no Plano Nacional de Educação de 2014-2024.
}

Periódico Horizontes - USF - Itatiba, SP-Brasil - e019008 
família e escola, o documento, em seu artigo 205, destaca que "a educação, direito de todos e dever do Estado e da família, será promovida e incentivada com a colaboração da sociedade" (BRASIL, 1988, p.?). Sobre o artigo citado, Resende e Silva (2016, p. 36) salientam que "[...] embora não se trate, aí, da relação família-escola propriamente dita, o texto de alguma forma remete a essa relação, na medida em que aponta a educação como responsabilidade comum do Estado e da família”. Nessa mesma linha, a Lei de Diretrizes e Bases da Educação Nacional (Lei no 9.394), de 20 de dezembro de 1996, também consagra em seu artigo 2ํa "educação como dever da família e do Estado" (BRASIL, 2013). E em seu artigo 12, a LDB 9394/1996 aborda o tema de forma mais específica e determinando as incumbências dos sistemas de ensino:

\footnotetext{
$\mathrm{VI}$ - articular-se com as famílias e a comunidade, criando processos de integração da sociedade com a escola;

VII - informar pai e mãe, conviventes ou não com seus filhos, e, se for o caso, os responsáveis legais, sobre a frequência e rendimento dos alunos, bem como sobre a execução da proposta pedagógica da escola;

VIII - notificar ao conselho tutelar do município, ao juiz competente da Comarca e ao respectivo representante do Ministério Publico a relação alunos que apresentem quantidade de faltas acima de cinquenta por cento do percentual permitido em lei.
}

Como podemos ver, na LDB 9394/1996, fica explícita a preocupação com a relação entre escola e família. Nota-se também que, de acordo com tal legislação, as iniciativas para fomentar a interação escola-família deverão ficar a cargo dos estabelecimentos de ensino e dos professores, como expresso no artigo 13 , inciso $\mathrm{VI}$, em que se estabelece que os docentes deverão "colaborar com as atividades de articulação da escola com as famílias e a comunidade" (BRASIL, 2013).

Por sua vez, em Portugal, com a promulgação da Lei nำ 7/77, o ensino primário e a educação pré-escolar não foram incialmente contemplados com a regulamentação do movimento associativo dos pais, ou seja, eles foram excluídos formalmente do processo, sendo que a abrangência da legislação estava apenas no ensino preparatório e secundário (SILVA, 2003). Em 31 de dezembro de 1979, foi aprovado o Decreto - Lei no 542/79, que instituiu o

Periódico Horizontes - USF - Itatiba, SP-Brasil - e019008 
Estatuto dos Jardins de Infância. De acordo com esse documento, ficou definido que é função do Conselho Pedagógico, do Conselho Consultivo e do diretor do Jardim de Infância promover a cooperação entre a escola e a família na educação pré-escolar. O Conselho Consultivo era criado, tendo a presença de dois representantes de pais, com obrigatoriedade de serem ouvidos. Entretanto, Silva (2003, p.142) afirma que, mesmo com a publicação deste decreto, específico para a educação infantil "[...] os pais continuam, porém, a não ter assento no Conselho Pedagógico, assim como no Conselho Escolar das escolas primárias. Para tal ainda terá de se esperar década e meia". Somente em 1984, o Decreto-Lei no 315/84 instituiu a extensão e aplicação da Lei no 7/77 que regulamentou a Lei das Associações de Pais em todos os graus e modalidades de ensino. Como vemos, no caso português, a ampliação da representatividade dos pais na escola, por meio das associações, levou quase dez anos para atender a todos os níveis de ensino, após a publicação da Lei no 7/77.

O quarto e último período explicitado por Silva (2003), nomeado como uma fase de desenvolvimento da participação parental em Portugal, compreende os anos de 1986 a 2000. Trata-se de um período de reformas no sistema educacional, de consolidação e desenvolvimento da participação parental. Em 1985, ocorreu a alteração do SNAP para Confederação Nacional das Associações de Pais-CNAP e em 1986, a publicação dos estatutos deste mesmo órgão. Neste mesmo ano, foi aprovada a Lei de Bases do Sistema Educativo (LBSE), Lei no 46 de 14 de outubro de 1986, na qual determinava-se a extensão obrigatória no processo de escolarização de seis para nove anos. Estabelecia também que

[...] a administração e gestão das escolas se deve orientar por <<princípios de democraticidade e de participação de todos os implicados no processo educativo >> (art.o 45., n.ㅇ) e que a direção das escolas <<é assegurada por órgãos próprios, para as quais democraticamente eleitos os representantes de professores, alunos e pessoal não docente, e apoiada por órgãos consultivos e serviços especializados (...) >> (art.o 45.․, n.․) (SILVA, 2003, p.146, grifos do autor).

Nota-se que, em Portugal, a LBSE não traz especificamente nenhuma novidade sobre a

Periódico Horizontes - USF - Itatiba, SP-Brasil - e019008 
representatividade dos pais. Percebemos também ênfase dada na tarefa das escolas em pautarse em um modelo de gestão democrática. No Brasil, não é diferente. A LDB 9394 de 1996 em seu artigo 14 estabelece que

Os sistemas de ensino definirão as normas da gestão democrática do ensino público na educação básica, de acordo com as suas peculiaridades e conforme os seguintes princípios:

I - participação dos profissionais da educação na elaboração do projeto pedagógico da escola;

II - participação das comunidades escolar e local em conselhos escolares ou equivalentes.

Desse modo, notamos que, tanto no Brasil quanto em Portugal, a legislação educacional, no final da década de 1980 e durante a década de 1990, recomenda e incentiva a gestão democrática nas escolas públicas, determinando a necessidade de promoção de um maior envolvimento e participação de todos os atores sociais da comunidade escolar, no processo educacional.

Em fevereiro de 1989 foi assinada a lei da autonomia das escolas em Portugal, que previa a democratização e participação de todos os interessados no processo educativo, tendo sido reconhecido o direito dos pais de questionarem a escola sobre os assuntos referentes a todo o processo educacional e os serviços prestados por ela. Após a publicação da lei da autonomia das escolas, foi também aprovado um novo Despacho no 8/SERE de 8 de fevereiro de 1989, que regulamentou o Conselho Pedagógico (CP) e seus respectivos órgãos de apoio. Nele, as Associações de Pais e o Conselho Consultivo integrariam um representante parental eleito em cada órgão, mesmo que na escola não houvesse Associações de Pais (SILVA, 2003). Assim, consolida-se, em Portugal, finalmente, o direito dos pais de se tornaram membros dos órgãos consultivos e decisórios da escola, tendo a sua representatividade regulamentada, o que poderia resultar, pelo menos do ponto de vista legal, em uma gestão escolar mais democrática. Entretanto, o autor salienta lacunas na legislação, primeiramente porque essa representação dos pais no Conselho Pedagógico e Escolar ainda não abrangia todos os níveis de ensino e, até aquele momento, o pré-

Periódico Horizontes - USF - Itatiba, SP-Brasil - e019008 
escolar e o primeiro ciclo não tinham representatividade parental nestes órgãos, e também porque "[...] faltam dados para saber qual a proporção das escolas dos 2.ํ e 3.ำ ciclos e secundários com a presença dos pais no seu $\mathrm{CP}$, qual a qualidade da intervenção destes e qual a sua articulação com a massa de pais da respectiva escola [...]" (SILVA, 2003, p.147).

Winter (2013), ao discutir sobre as perspectivas de implementação das políticas públicas, sublinha que para termos a compreensão do processo da política, é preciso que saibamos como os receptores dessas políticas públicas a respondem. Nesse sentido, o autor esclarece que "[...] muito poucos estudos de ciências políticas abordam a forma como os cidadãos reagem às políticas públicas [...]" (p.223). Desse modo, as reflexões de Winter (2013) são relevantes para compreendermos sobre a necessidade de estudos que focalizem os modos como os cidadãos recebem as políticas públicas, contribuindo para identificar lacunas no processo de implementação, bem como auxiliar os pesquisadores no aprofundamento dos estudos sobre a temática em questão.

Ainda sobre a legislação educacional portuguesa, no ano de 1990, por meio da Lei no 53, de 4 setembro de 1990 foi reforçado o papel interventor das Associações de Pais autorizadas pelo governo. Mais tarde, em 27 de novembro do mesmo ano foi instituída a nova lei (DecretoLei no 372/90) das Associações de Pais em substituição a lei anterior promulgada em 1977 . O documento da nova lei era mais completo e explicitava todos os direitos das Associações de Pais. Outra alteração, o Decreto Lei no 172 de 10 de maio de 1991, regulamentou os órgãos colegiados das escolas. Segundo essa legislação, os pais passariam a ter representatividade no Conselho de Escola ou de Área Escolar, e todos os encarregados de educação teriam direito à voto. Percebese, no caso da legislação portuguesa, um avanço significativo quanto à representatividade dos pais nos órgãos escolares. Nesse sentido, Silva (2003, p.150) afirma que este último decreto “[...] expressa uma vontade inequívoca do poder político em ter os pais dentro das escolas (em todos os órgãos têm direito a voto) e em tê-los no maior número possível”. Percebe-se, assim, que existia uma grande preocupação do Estado português em manter os pais como colaboradores no processo educativo dos filhos, o que se constituiria em uma forma de estreitar a interação

Periódico Horizontes - USF - Itatiba, SP-Brasil - e019008 
entre família e escola, regulamentando-a oficialmente.

Em 1993, é originado um outro documento importante em Portugal: o Despacho n.으 239/ME, de 20 de dezembro de 1993. Ele atualizou o Decreto-Lei n.o 372/90 nas escolas em que ainda não estava funcionando o modo de gestão instituído pelo Decreto Lei n.o $172 / 91^{9}$, ou seja, as escolas de pré-escolar e primeiro ciclo. Nesse contexto, Silva (2003, p. 152) destaca que

[...] a diferença essencial diz respeito à educação pré-escolar e ao 1. ciclo, passando agora as associações de pais (ou, na sua ausência, pais eleitos para o efeito) a ter um representante, respectivamente, no Conselho Pedagógico e no Conselho Escolar (ou dois no caso em que o Conselho Escolar agrupe mais do que uma escola. Em todos os órgãos que integram os pais têm direito a voto (art.ㅇ 4.ํ).

Como vemos, em Portugal, na década de 1990, os pais passam a ter o direito à efetiva participação na gestão escolar, tendo reconhecida a sua representatividade nos órgãos da escola, com direito ao voto e com abrangência em todos os níveis da escolarização básica. E nos casos em que a escola não havia constituído uma Associação de Pais no 1. ciclo e nos Jardins de Infância, a direção da escola ficaria incumbida de promover ações no início de cada ano letivo para eleição dos representantes dos pais (SILVA, 2003).

Desse modo, percebe-se o quanto foi lento o processo em Portugal, para ter uma legislação que atendesse e regulamentasse a participação dos pais nas Associações de Pais em todos os níveis de ensino, sendo que, no pré-escolar e o 1. ciclo, os pais ficaram alijados do direito à representatividade nos órgãos escolares por 20 anos (SILVA, 2003). Assim, em Portugal, podemos afirmar que existe uma lei específica para legitimar a formação das Associações de Pais nos estabelecimentos de ensino, superando os obstáculos para a sua implementação. Já no Brasil, como apontado por Silva e Resende (2016), embora ainda não exista uma lei específica para normatizar e oficializar as Associações de Pais, a menção a esse tipo de associação apareceu recentemente no Plano Nacional de Educação (PNE) para o período de 2014 a 2024. Podemos

\footnotetext{
${ }^{9}$ Após a publicação deste Decreto, Silva (2003) destaca que ele foi aplicado aproximadamente em 50 escolas de Portugal, e excluía o pré-escolar e o primeiro ciclo. Por isso a nova regulamentação da lei para atender a todas escolas e em todos os níveis de escolarização.
}

Periódico Horizontes - USF - Itatiba, SP-Brasil - e019008 
dizer, então, com base no pensamento de Silva (2003) sobre o conceito de participação, que ainda no Brasil os pais não têm seu direito de participação escolar legalizado e oficializado por meio de Associações de Pais, pois, como vimos a única menção foi feita recentemente em 2014 no PNE.

\section{Desvelando pontos: legislação portuguesa e brasileira}

Vimos anteriormente, no caso português, que a emergência da participação parental foi estimulada pelo Estado, mais do que pelos movimentos populares (SILVA, 2003). Entretanto, o autor sublinha que a análise dos documentos legais demostra uma visão escolacentrista da relação, ou seja, centrada na vertente escolar. Para tanto, o autor aponta dois aspectos da legislação que esclarecem tal afirmação. O primeiro, segundo o autor, é que "[...] em nenhum momento a legislação sugere meios de a escola poder aproximar-se ou actuar junto das famílias no sentido destas poderem desempenhar um papel mais interventivo junto dos seus educandos" (SILVA, 2003, p.186). O segundo aspecto apontado por Silva (2003), refere-se à lei das Associações de pais (Decreto Lei n. $372 / 90$ ) no tocante aos deveres e direitos dos encarregados da educação e das Associações de Pais. Silva (2003) lembra que o artigo 9o, desdobrado em oito alíneas, é intitulado Direitos das Associações de Pais, e o artigo 15 intitulado "[...] Direito especial dos titulares de órgãos de Associações de pais. Aparece um único artigo sobre <<deveres >> (art. 14으), mas, curiosamente, sobre <<Deveres dos órgãos directivos dos estabelecimentos de educação ou ensino>> [...]" (SILVA, 2003, p.189, grifos do autor). Resumidamente, o autor destaca um desequilíbrio na legislação portuguesa que destina os deveres às escolas e os direitos, aos pais. Como vimos com Silva (2003), a legislação se centra na vertente escolar, ela determina obrigações dos sistemas de ensino no intuito de fortalecer a interação entre escola e família, ao mesmo tempo em que também atribui e reforça o direito aos pais a participarem da vida escolar dos filhos, por meio de diversos mecanismos tais como, reuniões, integração nos órgãos da escola ou entrevistas individuais.

Quanto à legislação brasileira, Resende e Silva (2016) realizaram um estudo, envolvendo

Periódico Horizontes - USF - Itatiba, SP-Brasil - e019008 
uma análise documental desde 1988 até 2014, sobre como esses documentos tratam a relação entre família e escola. As autoras argumentam que alguns desses documentos expressam a educação escolar como um direito, e destacam a sua obrigatoriedade, sendo que a primeira relação dos pais com a escola é compulsória, ou seja, inicia-se quando os pais ou responsáveis matriculam seus filhos. Quanto à LDB 9394/1996, ao tratar das incumbências das escolas e dos professores nos seus artigos 12 e 13, normatiza a responsabilidade das escolas de criarem iniciativas de aproximação com as famílias, no entanto "[...] não há maiores detalhamentos na legislação a respeito das formas e critérios dessa articulação [...]" (RESENDE; SILVA, 2016, p.40). Percebemos, assim, que a legislação tanto brasileira quanto portuguesa não indica os mecanismos pelos quais as escolas podem desenvolver um papel mais interventivo e interativo com as famílias.

No caso português, um aspecto que merece atenção é o fato apontado por Silva (2003) sobre o tratamento desigual dado aos níveis de ensino pré-escolar e ensino primário, que iniciou com publicação da primeira Lei das Associações de Pais, na qual não estava incluída a representatividade dos pais nestes níveis de ensino por meio das associações. Em síntese, segundo o autor,

[...] só 10 anos depois de Abril é que as escolas do 1. ciclo vêem reconhecido o direito associativo de pais; só 20 anos depois é que os pais passam a integrar, como membros de pleno direito, o Conselho Escolar; só 25 anos volvidos sobre o 25 de Abril é que as escolas do 1. ciclo serão geridas e administradas de acordo com a legislação comum a todos os graus de ensino não superior[...] (SILVA, 2003, p.195).

Nesse quadro, questiona-se: quais foram os motivos que levaram o Estado português a permitir esse tratamento desigual da representatividade dos pais no ensino preparatório e secundário? E no Brasil, qual a atenção dada pela legislação ao tema da participação parental nestes níveis de ensino?

Em Portugal, Silva (2003) argumenta que essa diferença de tratamento legal pode estar Periódico Horizontes - USF - Itatiba, SP-Brasil - e019008 
relacionada às peculiaridades desses níveis de ensino, pois têm modos de funcionamento e realidades diferentes. Nesse contexto, Silva (1994) citado por Silva (2003), ensaia algumas hipóteses para tentar identificar essa diferença de tratamento da representatividade parental por parte do Estado. Diante disso, as hipóteses levantadas pelo autor estão relacionadas à composição social nestes níveis de ensino, sendo que há representação forte dos pais de classe popular no 1 을 ciclo, enquanto que, nos níveis subsequentes, a presença é demarcada pela maior representação da classe média. Essa forte representação das famílias populares reflete na liderança do movimento associativo de pais e "[...] corresponderá a uma menor <<capacidade〉> para os pais se organizarem a nível de cada escola e de constituírem como grupo de pressão, tanto face ao movimento associativo dos pais como face ao poder político" (SILVA, 2003, p.196, grifos do autor). Outra hipótese levantada pelo autor é em relação ao menor interesse do poder político pela composição social popular das instituições de ensino. Destaca-se também a hipótese de que, pelo fato de o movimento associativo dos pais ter, historicamente, uma composição social de classe média, a baixa representação desses grupos sociais nas escolas infantis, resulta em pouca pressão sobre o poder político. E, adicionalmente às hipóteses citadas, acresce-se também que é recorrente no pré-escolar e no 10 ciclo a frequência de contatos informais entre pais e professores, nestes níveis de ensino, justificando o baixo número de associações de pais, o que reduz a pressão sobre o poder político (SILVA, 2003).

Passamos agora a identificar a forma como a legislação brasileira trata esses primeiros níveis de ensino. No pré-escolar, atualmente denominado como educação infantil, Resende e Silva (2016) ao analisarem os documentos legais como: Plano Nacional de Educação (2001 e 2014-2024); Parecer CNE/CEB n.ํ 20/2009; Resolução CNE/CEB no 5/2009, fizeram um detalhamento sobre o tema da interação família e escola apontado pelos documentos. As autoras esclarecem que o Parecer CNE/CEB n. 20/2009 é o documento em que se verificou um maior detalhamento no que concerne às formas de interação entre família e escola. As autoras salientam também que este documento tem um item intitulado "A necessária e fundamental parceria com as famílias na Educação Infantil", no qual há recomendações para que os 
profissionais desenvolvam formas de tratamento adequadas para articular a relação com as famílias neste nível de ensino. Nesta parte do documento fica dada a visibilidade da importância da participação dos pais na vida escolar das crianças pequenas:

Quando a criança passa a frequentar a Educação Infantil, é preciso refletir sobre a especificidade de cada contexto no desenvolvimento da criança e a forma de integrar as ações e projetos educacionais das famílias e das instituições. Essa integração com a família necessita ser mantida e desenvolvida ao longo da permanência da criança na creche e pré-escola, exigência inescapável frente às características das crianças de zero a cinco anos de idade, o que cria a necessidade de diálogo para que as práticas junto às crianças não se fragmentem (BRASIL, 2009, p.13).

Desse modo, fica evidente a indispensável intersecção entre a escola e as famílias nesta modalidade de ensino. O documento também orienta, por exemplo, que os profissionais compreendam as famílias como parceiras, e que acolham as diferentes maneiras de organização familiar, respeitando as opiniões dos pais em relação aos seus filhos, e que a escola escute os pais por meio da sua participação juntamente com os professores e os demais profissionais da instituição nos Conselhos Escolares, bem como acompanhe os projetos didáticos (BRASIL, 2009).

Em síntese, as autoras salientam que

Em toda a legislação pesquisada, observa-se uma tendência a que o número de referências à articulação escolas-famílias seja maior nos documentos pertinentes à Educação Infantil e decresça com a progressão para níveis de ensino mais elevados. Esse fato talvez possa ser explicado pelas características da faixa etária correspondente à Educação Infantil e pelo fato de se tratar do primeiro momento de escolaridade formal da criança (RESENDE; SILVA, 2016, p.42).

Quanto a educação básica, Resende e Silva (2016, p.42, grifo do autor) argumentam que, no âmbito federal, observou-se uma propensão a “[...] a vincular a articulação escolas-famílias à questão mais específica da qualidade de ensino, reforçando-se, nos documentos legais, a noção de "mobilização", com foco na sociedade civil e não no interior das próprias escolas[...]". Ou seja,

Periódico Horizontes - USF - Itatiba, SP-Brasil - e019008 
o discurso sobre interação escola-família que permeia a legislação brasileira sobre o tema, ao colocar no centro da discussão a qualidade do ensino, dá um maior peso (desproporcional) à mobilização familiar e não aos diversos aspectos pedagógicos e administrativos do funcionamento das escolas.

No caso brasileiro, sobre a participação das famílias em órgãos escolares, vimos anteriormente que, tanto a Constituição de 1988 quanto a LDB de 1996, não especificam o termo família, mas apresentam, implicitamente, a necessidade de participação familiar na gestão da escola pública. Entretanto Resende e Silva (2016, p.45, grifo dos autores) ressaltam que

[...] não se pode falar de uma "forte regulamentação" desse nível de relação no âmbito federal, ficando a cargo dos estados e municípios o detalhamento de formas e critérios para a gestão democrática da escola e, consequentemente, para a participação das famílias nesse processo: tipos e funções dos órgãos colegiados, critérios para sua composição e funcionamento, a participação ou não da comunidade na escolha dos diretores de escola, etc.

Ao analisarmos a legislação brasileira e portuguesa, percebemos que a maior importância que permeia a relação da família com a escola na educação infantil, está mais visível no Brasil, e pode estar relacionada às características dessa modalidade de ensino, como apontado por Resende e Silva (2016) anteriormente. Entretanto, diferentemente do que acontece em Portugal, no Brasil não há uma "forte e clara regulamentação" sobre a participação parental em Associações de Pais. Enquanto em Portugal, mesmo que com alguns impasses na regulamentação das leis, os pais passaram, nas últimas décadas, a ter garantido o seu direito à representatividade e ao voto nas associações em todos os níveis de ensino regulamentado pela legislação. No Brasil, fica a cargo dos estados e municípios decidirem como será o tipo de participação dos pais na escola.

Resende e Silva (2016) argumentam que o PNE (2014-2024) confere maior ênfase à gestão democrática em relação aos documentos anteriores, bem como um aprofundamento nas

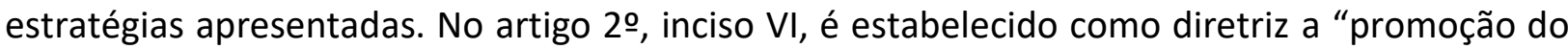
princípio da gestão democrática da educação pública" e no seu artigo 9o é estipulado o prazo de

Periódico Horizontes - USF - Itatiba, SP-Brasil - e019008 
dois anos para efetivação da lei (BRASIL, 2014). Quanto à formação de Associações de Pais, esta é assegurada na meta 19 do PNE, estratégia 19.4 (BRASIL, 2014).

E para finalizar essa seção, vale a pena refletir sobre a implicação dessas políticas públicas educacionais nas vidas das famílias. De acordo com Silva (2003, p.167-168), "[...] a escola exerce um papel normalizador, tentando chegar a todo lado [...]". Mas é preciso lembrar, segundo o autor, que a interação entre escola, família e comunidade é uma "relação entre culturas" e que tem implicações no modo como as famílias irão interagir com a escola, pois o desenvolvimento dessa relação significa "[...] desenvolver simultaneamente o espaço estrutural do Estado e o espaço-tempo doméstico [...]" (SILVA, 2003, p.172). Nessa mesma direção, Thin (2006) afirma que o modo como as famílias se relacionam com a escola tem uma clivagem social, ou seja, o modo de socialização das famílias da classe dominante não é o mesmo das camadas populares, pois a lógica de socialização, o modo de comunicação e a relação com o tempo variam conforme a classe social. Do ponto de vista desse autor, estamos tratando de lógicas socializadoras não somente diferentes, mas desiguais, pois a lógica socializadora das famílias de camadas médias e elites é consonante com a lógica socializadora escolar. Coincidência que nem sempre acontece com as famílias de camadas populares, cuja lógica socializadora pode estar mais distante do modo de socialização escolar.

Nessa perspectiva, essas reflexões nos remetem a pensar no conceito de capital cultural, criado por Bourdieu (1998) para compreender as desigualdades escolares, desmitificando a ideia de dom natural para explicar o sucesso escolar das crianças. O capital cultural implica a posse da cultura legítima pelos sujeitos ou pelos grupos sociais, ou seja, a cultura das classes que dominam os códigos eruditos, e que é também valorizada pela escola. Desse modo, a detenção de capital cultural, segundo o volume e estrutura desse capital, possibilita que as classes dominantes se diferenciem quanto ao gosto, o domínio da língua culta, as preferências em relações às práticas culturais (BOURDIEU, 2008), o que, consequentemente, influencia no modo de relacionamento das famílias com a escola, pois, a cultura da escola está em consonância com a da classe dominante, enquanto que para as classes populares está mais distante (BOURDIEU, 1998). Assim,

Periódico Horizontes - USF - Itatiba, SP-Brasil - e019008 
“[...] as frações mais ricas em capital cultural têm propensão a investir, de preferência, na educação dos filhos e, ao mesmo tempo, nas práticas culturais próprias e manter e aumentar sua raridade específica [...]" (BOURDIEU, 2008, p.112). Desse modo, ao refletirmos sobre os apontamentos teóricos de Silva (2003) e Bourdieu (2008) percebemos que a cultura é um fator que diferencia as famílias no que tange às percepções e ao modo como vão se relacionar com as escolas, bem como ao tipo de educação que poderão oferecer aos seus filhos.

Nesse sentido, o controle do Estado e a formulação das políticas públicas sobre o sistema educativo (re) produz desigualdades sociais, pois as famílias são responsabilizadas pelo sucesso ou insucesso no processo de escolarização dos seus filhos, enquanto que o " [...] Estado desresponsabiliza-se dos efeitos das políticas por si delineadas e impostas, ao mesmo tempo que culpa as vítimas por aqueles efeitos" (SILVA, 2003, p.35-36).

Diante disso, podemos supor que há, do ponto de vista do poder político, uma legislação que inscreve um tipo de relação escola família desencadeador de uma espécie de parentocracia ${ }^{10}$ (SILVA, 2003). Desse modo, conforme o autor, “[...] O Estado far-se-ia, pelo menos parcialmente, substituir pelos pais no seu controlo das escolas e dos professores. Um controlo à distância" (SILVA, 2003, p.189). Sendo assim, é um meio de o Estado controlar as ações da escola por meio dos pais, com a representatividade deles na gestão escolar, ao mesmo tempo em que eles são responsabilizados pela educação escolar de seus filhos.

Contudo, Winter (2013) traz uma importante contribuição sobre o processo de implementação das políticas públicas, pois é preciso saber como os receptores dessas políticas a recebem. Afinal, as políticas públicas não vão atender a todos os envolvidos no processo educacional de forma homogênea, já que estamos diante de uma relação entre culturas, com famílias de diferentes meios sociais, o que impacta no modo como elas irão participar do processo educacional dos seus filhos, bem como nas formas de relacionamento e intervenção na escola.

10 Conforme Nogueira (2011, p.81) ao embasar-se em Brown (1990) o conceito de parentocracia remete a mobilização dos pais em favor da causa escolar, e "[...] que tende a substituir o regime escolar de promoção pelo mérito e a diminuir o impacto da herança cultural".

$$
\text { Periódico Horizontes - USF - Itatiba, SP-Brasil - e019008 }
$$




\section{Considerações finais}

Pode-se dizer que a emergência da participação parental nos países do continente europeu teve como marco inicial o pós-guerra, que alterou a relação do Estado com a escola, a família e a sociedade. No entanto, se podemos afirmar que, em Portugal, houve um movimento associativo dos pais - embora tenha apresentado pouco impacto frente ao poder político - e uma forte regulamentação estatal para a participação parental em órgãos escolares, com a criação de uma lei específica que define os direitos e deveres das Associações de Pais; no Brasil, de acordo com a literatura estudada, não se verificou a consolidação de um movimento associativo de pais. Além disso, Resende e Silva (2016) esclarecem que, nos documentos analisados desde 1988 a 2014, a constituição das associações de pais encontra-se ausente na legislação brasileira aparecendo somente no Plano Nacional de Educação 2014-2024. É o que leva as autoras a dizerem que no Brasil não se pode falar de uma "forte regulamentação estatal" da participação das famílias na escola pública.

Vimos também que tanto a legislação portuguesa quanto a brasileira não sugerem meios e estratégias com os quais as escolas possam interagir com as famílias, já que os documentos legais regulamentam que as iniciativas de interação com as famílias sejam incentivadas primeiramente pela escola. Nesse sentido, quais os programas/projetos de incentivos desenvolvidos pelas escolas para articularem com as famílias e com que efeito?

Em estudo realizado pela Unesco em 2009, por meio de um levantamento de projetos visando a articulação escola-família desenvolvidos por escolas públicas em diversos municípios e estados brasileiros, os autores identificaram ser "[...] pequeno o número de iniciativas (projetos, programas ou políticas) em curso no Brasil desenhadas especificamente para estimular a relação escola-família [...]" (CASTRO; REGATTIERI, 2009, p. 32). No caso de Portugal, não temos referência a este respeito, mas Silva (2003) aponta a ausência de dados sobre a qualidade e intervenção da representação dos pais nos conselhos pedagógicos e os tipos de articulação

Periódico Horizontes - USF - Itatiba, SP-Brasil - e019008 
desenvolvidos com os demais pais da escola.

Contudo, diante do estudo das legislações brasileira e portuguesa sobre relação família escola e, de modo especial, sobre a participação parental na gestão escolar, podemos afirmar que não basta ter a participação dos pais regulamentada por lei, é preciso investigar os modos como os pressupostos legais estão sendo implementados pelas escolas, as condições (quase sempre desiguais) em que vivem e atuam as famílias, as comunidades e as escolas, para se ter uma visão mais ampliada sobre os impactos da legislação pertinente nas formas reais de interação entre escolas e famílias.

\section{Referências}

BRASIL. [Constituição Federal (1988)]. Constituição Federal de 1988. Promulgada em 5 de outubro de 1988. Disponível em:

http://www.planalto.gov.br/ccivil_03/constituicao/constituição.htm. Acesso em 01 dez. 2016.

BRASIL. Lei n. 4024, 20 de dezembro de 1961. Estabelece as diretrizes e bases da educação nacional. Brasília, DF, 20 de dez 1961. Disponível em:

http://www2.camara.leg.br/legin/fed/lei/1960-1969/lei-4024-20-dezembro-1961-353722publicacaooriginal-1-pl.html. Acesso em 01 dez. 2016.

BRASIL. Lei no 5.692, de 11 de agosto de 1971. Estabelece as diretrizes e bases da educação nacional. Brasília, DF, 11 de ago 1971. Disponível em:

http://www2.camara.leg.br/legin/fed/lei/1970-1979/lei-5692-11-agosto-1971-357752-

publicacaooriginal-1-pl.html. Acesso em 01 dez. 2016.

BRASIL. Ministério da Educação. Conselho Nacional de Educação. Parecer CNE/ CEB no 20/2009, de 11 nov. 2009a. Revisão das Diretrizes Curriculares Nacionais para a Educação Infantil. Diário Oficial da União, Brasília, DF, 9 dez. 2009; Seção 1:14.

BRASIL. Lei de Diretrizes e Bases da Educação Nacional: Lei no 9.394, de 20 de dezembro de 1996, que estabelece as diretrizes e bases da educação nacional. 8. ed. Brasília, DF: Edições Câmara, 2013. Disponível em: http:// bd.camara.gov.br/bd/bitstream/handle/bdcamara/2762/ldb_5ed.pdf. Acesso em: 08 dez.2016.

BRASIL. [Plano Nacional de Educação (PNE)]. Plano Nacional de Educação 2014-2024 [recurso

Periódico Horizontes - USF - Itatiba, SP-Brasil - e019008 
eletrônico] : Lei no 13.005, de 25 de junho de 2014, que aprova o Plano Nacional de Educação (PNE) e dá outras providências. - Brasília: Câmara dos Deputados, Edições Câmara, 2014. 86 p. - (Série legislação; n. 125).

BOURDIEU, Pierre. A escola conservadora: as desigualdades frente à escola e à cultura. In: NOGUEIRA, Maria Alice; CATANI, Afrânio (Orgs.). Escritos de Educação. Petrópolis, RJ: Vozes, 1998. p.39-64.

BOURDIEU, Pierre. Os três estados do capital cultural. In: NOGUEIRA, Maria Alice; CATANI, Afrânio (Orgs.). Escritos de Educação. Petrópolis, RJ: Vozes, 1998. p.71-79.

BOURDIEU, Pierre. A distinção: crítica social do julgamento. Inserir edição. Porto Alegre: Editora Zouk, 2008.

NOGUEIRA, M. A. Família e escola na contemporaneidade: os meandros de uma relação. Educação e Realidade, v. 31, n. 2, p. 155-169, 2006.

NOGUEIRA, Maria Alice. Capital Cultural. IN: VAN ZANTEM, Agnès. (Coord.). Dicionário de Educação. Petrópolis, Rio de Janeiro: Vozes, 2011. p.80-82.

CASTRO, M.; REGATTIERI, M. (Org.). Interação escola-família: subsídios para práticas escolares. Inserir edição. Brasília, DF: Unesco, MEC, 2009.

RESENDE, Tânia de Freitas; SILVA, Gisele Ferreira da. A relação família-escola na legislação educacional brasileira (1988-2014). Ensaio: aval. pol. públ. Educ., Rio de Janeiro, v.24, n. 90, p. 30-58, jan./mar. 2016.

SILVA, P. Escola-Família, uma relação armadilhada: interculturalidade e relações de poder. Inserir edição. Porto: Afrontamento, 2003.

SILVA, Pedro; STÖER, Stephen R. Do pai colaborador ao pai parceiro: a reconfiguração de uma relação. In: SILVA, Pedro; STÖER, Stephen R. Uma relação em processo de reconfiguração. Porto- Portugal: Porto Editora, 2005. p.13-28.

THIN, Daniel. Para uma análise das relações entre famílias populares e escola: confrontação entre lógicas socializadoras. Revista Brasileira de Educação, v. 11, n. 32, p. 211-225, maio/ago. 2006.

WINTER, Soren. Perspectivas de implementação: status e reconsideração. In: PETERS, G. \& PIERRE, J. Administração Pública Contemporânea. São Paulo: Editora UNESP, 2013. p.209-228.

Recebido em março de 2018.

Periódico Horizontes - USF - Itatiba, SP-Brasil - e019008 
Aprovado em outubro de 2018. 